\title{
Academic reference service over electronic mail
}

\author{
By Ann Bristow
}

\section{Tips for offering a popular and important service}

- eference service using electronic mail has been around for a while in academic libraries. The chatter on electronic discussion groups and in meetings at ALA suggests, however, that it is not thriving. No one describes "heavy" use of such a service and yet some libraries decide against initiating the service because of a fear that they will not be able to handle the volume. An assistant director of a large research library asked colleagues at a recent ALA meeting if other libraries had taken this "leap into the future" having just discovered, she reported, that one of the libraries under her supervision had begun to offer the service without requesting her approval. She was worried.

She need not have been. At Indiana University in Bloomington, Indiana, we began offering this service in 1987 as part of the libraries' component of an electronic "Academic Information Environment." It appears from what may be gathered informally that its use is, while not heavy, at least heavier than that of other academic libraries that speak of their experience.

From May through July 1991 (a quieter time of year) the Main Library Reference Department was contacted over electronic mail by 51 different users and had a volume of 330 questions and replies. Twenty-one of those users were faculty members, 14 were graduate students, 15 were staff members, and one was an undergraduate. One graduate student who maintained his computing account had moved to Washington State and contacted us from there; he intended to continue to use our services from his new location. He felt it was still the most convenient option available.

The greatest number of inquiries concerned addresses, phone numbers, prices, and incomplete citations (in various languages). Another group sought factual information; one associate instructor uses the service to double check "facts" cited in undergraduate papers. Some sought a "start" on a larger research problem. Very rare in our experience is the "inappropriate" question-too large or too vague.

\section{Surveying e-mail users}

In order to try to get a better understanding of our experience, to identify our clientele, and to consider improvements and modifications, a very brief survey was sent out to these users over electronic mail. Four questions were asked:

1) Do you do a great deal of your work (including correspondence) using computers? Or would you characterize your use of computers as occasional?

2) Have you ever come to the Main Library Reference Department and asked a question in person? Have you ever telephoned a question to that location?

3) If your answer to question 2 was positive, can you compare the usefulness of these ways of getting answers to your questions? (Does one fit in best with your work habits, do you get better service using one over the other, etc.?)

4) Could we modify the design or handling of the electronic service in any way that would make it more useful to you?

The first fact that our survey confirmed is that some behavior over electronic mail is different. The response rate was 80 percent; 60 percent of the replies were received within 24 
hours. That alone answered our first question: most (but not all) described themselves as using computers on a daily basis in many aspects of their work.

Answers to the second and third questions are harder to generalize. A few stated that they only communicate with us over e-mail; a larger number reported using all three methods of communicating. The telephone was the least popular by far, valued only for "emergencies." Several noted their frustration when asking questions in person and the interview is interrupted by a ringing phone; it was suggested that we train everyone to use e-mail and abandon the phone. The ability to discuss and refine a complex question in person was noted as very important by several.

\section{It was suggested that we train everyone to use e-mail and abandon the phone.}

Answers to the fourth question were perfectly delightful. Our services were described as "great"; we were enjoined to "keep up the good work"; half a dozen replied that they welcomed the opportunity to say "thank you." Very few had specific suggestions for improvements or modifications to the service. But they did have a great deal to say about two other issues.

In response to budget cuts and with the advice of a faculty committee, the library had just severely curtailed a popular campus document delivery service. Many respondents wanted to know to whom they could complain about this decision and observed that it was an extremely valuable service. Another significant number of respondents asked when more databases would be offered over the campus network; mentioned more than once were Books in Print, Dissertation Abstracts, ERIC, and Psychological Abstracts.

Library users are typically too generous in evaluating services and it is with that awareness that we tried to read the replies. It took discipline, however, to remind ourselves of that fact in reading the enthusiastic appraisal of the service and of our performance. Librarians sometimes worry about the isolated, anonymous nature of the electronic future. The survey confirmed what we had already noticed: each user-name has its own personality and most are extremely polite. Half the replies we send out routinely receive a "thanks again" within a few hours. It is just different, not less human, not dehumanizing.

\section{Some useful tips}

Apart from recounting our pleasure, there may be a few observations and principles that can be drawn from our experience and from the survey that many be helpful to other libraries:

1) In order for reference service using email to be generally useful it must be part of a larger electronic framework: a campus information system, an option with the online catalog, etc. Simply announcing an e-mail address in a printed campus newsletter and waiting for business is not likely to succeed.

2) The service will be used most by people who have integrated computing into all aspects of their work and communication. An electronic reference service will not drive that choice but will be a useful service to those who have made it.

3) Describe the service as clearly and succinctly as you can. In our system a selection from the top menu of "Reference Services" prompts another menu asking where to send the question (the Reference Department, one of 15 branch libraries, etc.). A few months after the survey described here, another option was added at the bottom of the top "Library Services" menu entitled simply "Ask a Librarian." Questions addressed to that selection are forwarded to Reference and the volume of questions we receive has tripled (over that described earlier). A higher percentage of questions are now referrals to Circulation or other units but we are receiving at least twice as many "real" reference questions.

4) Include a description of service param eters (what kinds of questions can I use this service for?). The screen a user is supplied in our system says simply "Enter the text of your question here." What a "reference question" is may not be easily understood. We receive several questions a week with no text and guess it is a user trying to figure out what this service is and if it has any relevance or utility. We plan to add examples (modified from those actually put to us) of directory and factual queries.

5) Describe pick-up times: do you plan to check daily, hourly, every day, every "working" day? Though it may be hard to promise turn-around time, an idea of how often you are looking at the mailbox will give the user an (Cont. on page 637) 


\section{Four Innovative Ways to

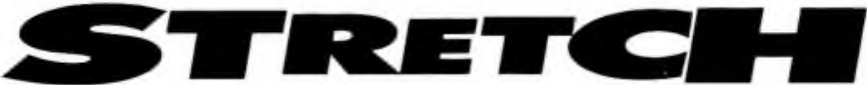 Your Serials Budget}

In Response to the Serials Budget Crisis

Because we're keenly aware of the severe budget cutbacks most libraries face, we've chosen to limit the average price increase on any of our 41 serial titles to the U.S. inflation rate - currently less than 3.5 percent.

Plus, we will provide new subscribers with a substantia! free allowance for full-text document delivery service a subscription benefit unique to Cambridge Scientific.

Major budget cuts are a fact of life in libraries around the world. The spiralling cost of serial titles has compounded this problem.

For 1993, Cambridge Scientific Abstracts has decided to respond in four innovative ways to help libraries get the most of their serials budget.
1.

Prices that remain steady. Cambridge Scientific will not increase the price on any of its serials more than the U.S. rate of inflation - currently less than 3.5 percent. So while other journal publishers are increasing prices as much as 30 percent, you can still access a tremendous amount of published literature in as many as 41 specialized fields with very little increase in cost.

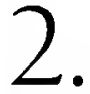

FREE allowance on document delivery. Free with your new subscription to any CSA journal, you will receive a generous allowance of $\$ 150$ to $\$ 300$ worth of full-text documents through CARL Systems' UNCOVER 2 or Engineering Information Inc. Once your allowance is used up, you will continue to enjoy substantial discounts on full-text document delivery.

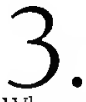

Package discounts of up $1050 \%$. Cambridge Scientific has grouped its journals and databases - into 13 major areas of science and technology. When you select an entire group, you will get a package discount of up to 50 percent off the individual subscription rates. Those are noticeable savings.

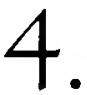

Preferred rates for networking. When you subscribe to any of the CSA print journals, you automatically qualify for substantial discounts on the magnetic tape version for your local or wide-area networks. So you'll have campus- or company-wide access for less!

See for yourself the cutting-edge quality of the journals Cambridge Scientific Abstracts has to offer. Call:

\section{1-800-843-7751}

(Ask for Journal and Tape Services.)

today to get your FREE catalog and FREE sample journals.

Cambridge Scientific Abstracts • 7200 Wisconsin Avenue, Bethesda, MD 20814 U.S.A. Toll-free: 1-800-843-7751 • Overseas \& MD: (301) 961-6750 FAX: (301) $961-6720$ 
Since the initiation of reference roving, three new dial-in services (Lexis/Nexis/Medis, Dialog/ Classmate, and Univnet), a Latin American wire service, and two CD-ROM databases (Million Dollar Directory and National Newspaper Index on Infotrac) have been added. Three Wilson databases (Humanities, Social Sciences, and General Science Indexes) were mounted on our NOTIS system and the UMI databases were moved onto our MultiPlatter network, along with PAIS and GPO. Having the roving service already in place, we were able to effectively introduce the new systems to our patrons.

\section{Conclusion}

A poll of the reference staff a year later indicates that our staff unanimously think reference roving is worthwhile and should be continued. It makes staff more accessible and allows time for in-depth help on an individual basis. Roving provides the opportunity for a pro-active approach and a first-hand view of how patrons use electronic resources. It also helps relieve the stress felt at the reference desk by allowing referrals to the reference rovers.

Several recent articles, including Charles A. Bunge's "CD-ROM Stress" (Library Journal, April 15, 1991), emphasized that this proliferation of electronic resources has led to the rise of technostress in reference departments. Reference roving at Boston College's O'Neill Library has proved to be a successful approach for dealing with these problems and meeting our patrons' needs.
(Academic reference cont. from page 632)

idea of how fast the service may or may not be and how appropriate to present need. (We have been checking five times a day, seven days a week; but we had not communicated this to our users and a few have expressed disappointment that they did not get speedier replies. They may have imagined some ongoing constant monitoring.)

6) Pick up the messages regularly and monitor that responses have been sent. In our case the office manager assumes this task Monday through Friday. She then gives the questions to the librarian or staff member on duty at the Reference Desk. Another model might be to rotate the responsibility on a weekly basis to individual staff members. Whatever the model, it is important that the expertise of the staff be utilized when appropriate. Any question we receive on cinema goes automatically to our resident expert. One of the benefits of email is that it allows you to take advantage of such expertise. It frees both librarian and patron from the lottery they each face in handling reference transactions over the telephone or in person-when an answer to the question is most often attempted immediately by the person on duty, whatever subject or language expertise they may or may not possess.

7) Cite the source your "fact" comes from. This need not be in correct and complete bibliographic form, unless that is requested. That associate instructor who uses us to double check facts his students use in their papers has reminded us again that one woman's fact is another's mistake. Unless you plan to check the fact in six different sources (finding three different answers), pick a reputable source and say what it is. This principle is hardly unique to reference work in an electronic setting. That it's worth mentioning here probably reflects the fact that librarians and staff accustomed to the generally unmonitored, oral, one-on-one style of most reference work may respond differently to written communications which may be viewed (and reviewed) by their colleagues. It is a good reminder of the form and substance of the answers we give to all questions.

8) This service will likely stimulate demand for other library services such as document delivery, databases beyond our own line catalogs, and expert systems designed within specific ranges of inquiry. The responses we received about the delivery service and additional databases over the network were not motivated only by local events but by a vision of the total array of services desired from the scholar's own workstation.

Even in the richest, most intelligent online environment, however, there is probably a useful niche for a "reference" option. Such an option requires the user to know only what she wants to know and to answer no questions about her question before she can ask it! It is a service users appreciate.

\section{Note}

'Described in this joumal by Miriam Bonham, "Library services through electronic mail," CERL News 48:9 (October 1987): 537-38. 